University of Nebraska - Lincoln

DigitalCommons@University of Nebraska - Lincoln

Faculty Publications from Nebraska Center for Research on Children, Youth, Families, and Schools

$11-22-2019$
Children, Youth, Families \& Schools, Nebraska Center for Research on

\title{
Longitudinal and Geographic Trends in Family Engagement During the Pre-kindergarten to Kindergarten Transition
}

\author{
Susan M. Sheridan \\ Natalie A. Koziol \\ Amanda Witte \\ Iheoma Iruka \\ Lisa Knoche
}

Follow this and additional works at: https://digitalcommons.unl.edu/cyfsfacpub

Part of the Bilingual, Multilingual, and Multicultural Education Commons, Child Psychology Commons, Counseling Psychology Commons, Developmental Psychology Commons, Early Childhood Education Commons, Educational Psychology Commons, Family, Life Course, and Society Commons, and the Other Social and Behavioral Sciences Commons

This Article is brought to you for free and open access by the Children, Youth, Families \& Schools, Nebraska Center for Research on at DigitalCommons@University of Nebraska - Lincoln. It has been accepted for inclusion in Faculty Publications from Nebraska Center for Research on Children, Youth, Families, and Schools by an authorized administrator of DigitalCommons@University of Nebraska - Lincoln. 


\title{
Longitudinal and Geographic Trends in Family Engagement During the Pre-kindergarten to Kindergarten Transition
}

\author{
Susan M. Sheridan, ${ }^{1}$ Natalie Koziol, ${ }^{1}$ Amanda L. Witte, ${ }^{1}$ \\ Iheoma Iruka, ${ }^{2}$ and Lisa L. Knoche ${ }^{1}$ \\ 1 University of Nebraska-Lincoln, Lincoln, NE, USA \\ 2 HighScope Educational Research Foundation, Ypsilanti, MI, USA
}

Correspondence - Susan M. Sheridan ssheridan2@unl.edu

\begin{abstract}
The transition to kindergarten is foundational for children's future school performance and families' relationships with the educational system. Despite its well-documented benefits, few studies have explored family engagement across the pre- Kindergarten (pre-K) to kindergarten transition nor considered the role of geographic context during this period. This study examined trajectories of family engagement across the pre- $\mathrm{K}$ to kindergarten transition, and identified whether engagement differs for families in rural versus urban settings. Participants were 248 parents of children who participated in publicly funded pre-K programs and transitioned 1 year later into kindergarten. Home-based involvement increased from pre-K through kindergarten. School-based involvement increased during pre-K and decreased through the end of kindergarten. Structural and relational communication remained stable during pre-K and decreased through the end of kindergarten. Compared to urban parents, rural parents reported less home-based involvement, structural communication, and relational communication. Implications for practice and policy are explored.
\end{abstract}

Keywords: Parent engagement, Parent involvement, Home-school communication, Pre-K to kindergarten transition, Rural and urban schools

Published in Early Childhood Education Journal (2020) 48:365-377

DOI: $10.1007 / \mathrm{s} 10643-019-01008-5$

Copyright (C) Springer Nature B.V. 2019. Used by permission

Published 22 November 2019. 


\section{Introduction}

Parents play a critical role in the early learning and development of their children. They create opportunities for children to explore their environments and interact meaningfully with people and objects. They provide a context within which cognitive, social, emotional, behavioral, and physical development can be stimulated. Parents establish relationships and connections within and outside of the home that are important for children's overall academic and social-emotional learning (NASEM 2016).

Parents are in a position to provide consistent stimulation and support for children's learning during early school experiences (i.e., preKindergarten; pre-K), and during educational transitions to kindergarten. Involvement of parents during the pre-K period is related to growth in children's preliteracy skills (Arnold et al. 2008) and social competencies (Sheridan et al. 2010). The transition to kindergarten is a particularly sensitive time, as it sets the foundation for children's future school performance and families' relationships with the educational system (Malsch et al. 2011; Schulting et al. 2005). Difficult transitions are associated with adjustment problems (Margetts 2009), and children who enter school behind their peers in important skill areas are at risk for falling further behind as they progress through school (McClelland et al. 2006). Given that parents are among the primary influencers of children's early learning across the pre-K to kindergarten transition, it is important to understand their engagement during that period.

Parent engagement practices are likely influenced by the contexts within which parent-child and parent-teacher interactions occur. One important context likely to impact practices and patterns associated with parental engagement is the community within which children live. Variations across community settings likely contribute to different forms of family engagement (Keys 2015), and subsequently children's outcomes (Miller and Votruba-Drzal 2013). Conceptually, geographic context (in this case, rural or urban setting) represents an important system that could potentially impact how a child and family experience the pre-K to kindergarten transition. However, little is known about how living in a rural or urban community contributes to parent engagement during this period of transition. 


\section{Theoretical Framework}

Ecological theory provides a useful framework for understanding the various systems and contexts that influence children's development (Bronfenbrenner 1977). Most proximal are microsystems, comprised of practices, interactions, and learning activities in the home and in formal and informal learning environments that play a role in development. These microsystems of home and school experienced by children create a broader system that also impacts children's development (i.e., the mesosystem) comprised of relationships between microsystems, such as between children's parents and teachers/providers. More distal is the exosystem, which includes the geographic context within which children, families, and schools reside (e.g., rural/urban/suburban locales and their distinct characteristics). The exosystem influences the types of experiences, opportunities, and resources that are available. Broader yet are macrosystem variables whose overarching cultural, political, and normative nuances permeate the exo- (communities), meso- (relationships) and micro- (immediate home and school environments) system levels. Finally, the chronosystem represents how systems and their influences change over time in relation to children's ongoing developmental processes and the micro-, meso-, exo- and macro-systems. Attention to the chronosystem allows for the recognition that timing of engagement may impact immediate and long-term childhood trajectories. Furthermore, the nature and effects of engagement and its various forms may differ across developmental periods.

To capture fully the nature and effects of various influences on children's learning, we need to understand how systems operate and interact, immediately and over time. The purposes of this study are to determine (a) the changing course of family engagement across the pre-K to kindergarten transition, and (b) whether family engagement practices and trajectories differ for families living in rural versus urban communities. As an ecologically oriented study, we are honing in on aspects of family engagement that permeate systems. Specifically, we explore family engagement (a) within home and school microsystems, (b) as reflected in mesosystemic relationships between parents and teachers, (c) within the context of geographic location (rural, urban) at the level of the exosystem, and (d) across the pre-K to kindergarten transition, reflecting the chronosystem. In the present study, we use the term "parent" to refer 
to an adult who holds primary responsibility for the care and well-being of a child; "parent engagement" and "family engagement" are also used interchangeably.

\section{Multidimensionality of Family Engagement}

Many terms have been used to characterize roles and relationships between families and schools, such as parent involvement, parent-teacher partnership, home-school collaboration, and the like. We use the term "engagement" intentionally because it encompasses the many ways that parents participate in their children's learning, including home-based practices to provide stimulation and learning support (e.g., shared book reading), involvement in opportunities provided by educators at school (e.g., volunteering at school events), exchange of information and communication with educators (e.g., sending messages), and creation of positive relationships or partnerships with teachers (e.g., making joint decisions about learning goals).

Parenting practices in the home are important for young children's overall school readiness (Sheridan et al. 2011; Weigel et al. 2006). Children whose parents are actively involved with their young child at home demonstrate capacities to interact prosocially, manage frustration, and solve problems (Denham et al. 2007). Parent engagement in young children's learning experiences during the preschool period has been linked to early vocabulary and language skills (Hart and Risley 1995; Hindman and Morrison 2012); alphabet knowledge (Sénéchal 2006); self-regulation, cooperation and compliance (Hindman and Morrison 2012); numeracy skills (Napoli and Purpura 2018) and social-behavioral skills (Sheridan et al. 2010). Furthermore, early reading experiences in the home predict later language and literacy readiness in kindergarten and reading skills in early elementary school, demonstrating long-term effects of early parent engagement in home literacy practices (Forget-Dubois et al. 2009).

Parenting practices at school represent an additional context for demonstrating support for children's learning. Parenting practices such as visiting the school, attending conferences, or volunteering promote connections between adults in children's most proximal learning environments- home and school. In both explicit and implicit ways, these school-based engagement practices could help parents increase their 
knowledge about upcoming events, acquire strategies to support their children's development and learning, or gain resources to benefit their family. Benefits of parents' school-based involvement to children are experienced when information, skills, or access to resources are transferred into meaningful parent-child interactions outside of school (Lee and Bowen 2006).

Interactions that parents have with their child's early educators are also important. Intervention research investigating the efficacy of a family-school partnership intervention found that the quality of the parentteacher relationship mediates the effects of the intervention on students' social skills (Sheridan et al. 2012) as well as home and school behaviors (Sheridan et al. 2017a, b). Communication practices between home and school are often identified as a determinant of parent-teacher relationships, and a high priority for parents and teachers alike (Lang et al. 2016). Communication between parents and teachers can vary in form (how communications are delivered) and nature (what is communicated), and can be structural (i.e., focused on school practices or information) or relational (i.e., focused on interpersonal dynamics such as trust). Communication between parents and teachers is important for enhancing both teacher and parent outcomes; high quality communication between parents and teachers has been found responsible for improving teachers' practices (Sheridan et al. 2018) as well as increasing parents' participation in their children's schooling (Kohl et al. 2000; Waanders et al. 2007).

\section{Family Engagement Across Rural and Urban Settings}

Ecological systems likely influence the myriad ways that family engagement manifests. However, most of the research on family engagement has been conducted in urban settings with little attention to the rural context (Semke and Sheridan 2012), despite documented differences in parenting practices and family-school connections between rural and urban settings. Studies that have explored geographic context and parent activities generally find differences in frequency of engagement behaviors between urban and rural samples, in favor of urban. Such studies tend to focus on a notion of family engagement that is limited to parent practices at the school (Prater et al. 1997), or assess perceptions at one point in time (Keys 2015). There is a dearth of information about 
patterns of family engagement using a multidimensional conception of family engagement, across the pre-K to kindergarten transition, and how the patterns may vary as a function of community context.

Rural communities have many assets that enhance the potential for family engagement (McBride et al. 2002). Rural communities tend to value collaboration and cooperation and place a high priority on family and relationships. Rural schools are generally comprised of dense and intergenerational relationships and networks, and limited bureaucracy allows for direct communication between home and school. They are small in size, and often serve as the cultural center of the community. However, by definition, rural communities are isolated, which results in limited access to resources. Rural schools often have small class sizes, but the potential benefit is attenuated by teachers with lower levels of educational attainment, limited specialization in areas such as special education and bilingual certification, and fewer professional development experiences (Lavalley 2018; Player 2016). Inadequate funding for rural schools is a significant barrier, with rural districts receiving on average just $17 \%$ of state education funding (Showalter et al. 2017). Additional challenges facing rural schools and families include distance to schools and agencies, dispersed social networks, and limited educational, health, mental health, and recreational opportunities for rural families. Furthermore, despite the fact that student populations in rural areas have decreased overall, the number of English Language Learners and minority student populations have increased (Lavalley 2018). Structural realities and cultural shifts in rural communities may potentially limit rural parents' abilities to engage with schools.

\section{Current Study}

There is a need to understand the degree to which parents are engaged with children's learning across the pre-K to kindergarten transition, and whether geographic context (rural or urban) influences family engagement over time. Our specific research questions are:

1. Does parent-reported family engagement (home-based and schoolbased involvement; and structural and relational communication) change from entry into pre-K through the kindergarten year?

2. Does parent-reported family engagement (home-based and schoolbased involvement; and structural and relational communication) differ for children in rural versus urban schools? 


\section{Methods}

\section{Setting}

The current study was conducted in rural and urban communities in one Midwest state. Two hundred forty-eight (248) Pre-K children were enrolled in ten rural school districts/ community agencies, and two urban school districts. Sixteen of the 248 pre-K children transitioned out of their initial school district into twelve new districts in kindergarten, yielding a total representation of 24 school districts when children were in kindergarten. The National Center for Education Statistics Office of Management and Budget (NCES 2000) categorizes school districts into one of 12 categories within four locale codes: city and suburb (defined by population, including small, midsize, large) and town and rural (defined by population and proximity to urban centers, including fringe, distant, remote). For our purposes, all cities and suburbs are considered "urban", and town and rural are considered "rural". Thus, our final sample is comprised of two pre-K and seven kindergarten urban districts, and 10 pre-K and 17 kindergarten rural districts.

Pre-K teachers taught in classrooms operated within school districts or Head Start programs. All classrooms were publicly funded. The majority of pre-K classrooms were located within elementary schools $(n=51)$; the remaining classrooms were located in stand-alone buildings or community agencies $(n=14)$. Rural pre-K classrooms were mostly half-day (65\% half-day; 35\% full-day) and urban pre-K classrooms were nearly equally divided between half- and full-day (54\% half-day; $46 \%$ full-day). Pre-K classroom size ranged from 9 to 20 students in rural classrooms, and 14-20 students in urban classrooms. Children transitioned into 150 kindergarten classrooms in 84 schools. Kindergarten classrooms were in session a full day during the academic year. Kindergarten classroom size ranged from 10 to 26 students in rural classrooms, and 13 to 26 students in urban classrooms.

\section{Participants}

Participants were enrolled in a longitudinal study intended to examine the learning experiences of children from pre-K through Grade 3 in rural and urban communities in the Midwest. The current study includes data that were collected across the pre-K through kindergarten 
transition. The present study includes 248 children (with missing data and exclusions described in the data analysis plan). Children whose parents were fluent in English and/or Spanish were eligible for participation. Parents were mostly female (92\%), 53\% identified as White 24\% as Hispanic/Latino, 16\% Black/African American, and $7 \%$ as a different race not listed above or multiple races. Sixty-five pre-K teachers participated and had between 1 and 5 children from their classrooms enrolled in the study; 122 kindergarten teachers were involved with 1-5 children from their classrooms in the study. Specific demographic details for pre-K and kindergarten teachers, urban and rural family participants are provided in Table 1. Chi square analyses exploring differences between rural and urban classroom contexts were conducted; these results also are in Table 1.

\section{Procedures}

Data were collected at three time points: the end of the fall and end of the spring semesters of children's pre-K year, and the end of the spring semester of children's kindergarten year (Time 1 [T1], Time 2 [T2] and Time 3 [T3], respectively). Teachers completed questionnaires via a secure, web-based platform. Parents completed questionnaires during a meeting with a research assistant in their homes, at the school, or at a convenient location within the community. Fifteen percent of families completed the survey in Spanish at T1 and T2, and 16\% at T3.

\section{Measures}

Family engagement at home and school, and structural and relational communication with the child's teacher, were collected using two parent-report measures.

\section{Family Involvement Questionnaire}

The Family Involvement Questionnaire (FIQ; Fantuzzo et al. 2000) is a multidimensional scale of family engagement for children in pre-K through first grade. The scale consists of 36 items across three factors tapping home-based involvement (parent engagement in home-based learning activities), school-based involvement (parent participation in 
Table 1 Characteristics of parents and teachers across urban and rural settings

\begin{tabular}{|c|c|c|c|c|c|c|c|c|}
\hline \multirow[b]{2}{*}{ Parents } & \multicolumn{2}{|c|}{$\begin{array}{c}\text { Total } \\
\mathrm{N}=248 \\
(100 \%)\end{array}$} & \multicolumn{2}{|c|}{$\begin{array}{c}\text { Urban } \\
\mathrm{N}=132 \\
(53.2 \%)\end{array}$} & \multicolumn{2}{|c|}{$\begin{array}{c}\text { Rural } \\
\mathrm{N}=116 \\
(46.8 \%)\end{array}$} & \multicolumn{2}{|c|}{$\begin{array}{l}\text { Urban vs. rural } \\
\text { comparison }\end{array}$} \\
\hline & $\mathrm{N}$ & $\%$ & $\mathrm{~N}$ & $\%$ & $\mathrm{~N}$ & $\%$ & $\chi^{2} / \mathrm{LRT}(\mathrm{df})$ & $p$ \\
\hline Relationship to child & & & & & & & $17.22(2)$ & $<.001$ \\
\hline Mother & 224 & 90.3 & 116 & 87.9 & 108 & 93.1 & & \\
\hline Father & 19 & 7.7 & 11 & 8.3 & 8 & 6.9 & & \\
\hline Other ${ }^{\mathrm{a}}$ & 5 & 2.0 & 5 & 3.8 & 0 & 0.0 & & \\
\hline Language most often spoken at home with child & & & & & & & $5.89(1)$ & .015 \\
\hline Only English & 189 & 76.2 & 89 & 67.4 & 100 & 86.2 & & \\
\hline Other ${ }^{b}$ & 59 & 23.8 & 43 & 32.6 & 16 & 13.8 & & \\
\hline Race/ethnicity & & & & & & & $119.70(3)$ & $<.001$ \\
\hline Black & 40 & 16.1 & 40 & 30.3 & 0 & 0.0 & & \\
\hline Hispanic or Latino & 60 & 24.2 & 36 & 27.3 & 24 & 20.7 & & \\
\hline Other ${ }^{\mathrm{c}}$ & 16 & 6.5 & 12 & 9.1 & 4 & 3.5 & & \\
\hline White & 132 & 53.2 & 44 & 33.3 & 88 & 75.9 & & \\
\hline Highest level of education & & & & & & & $30.58(4)$ & $<.001$ \\
\hline Less than HS diploma/GED & 31 & 12.5 & 25 & 18.9 & 6 & 5.2 & & \\
\hline HS diploma/GED & 66 & 26.6 & 37 & 28.0 & 29 & 25.0 & & \\
\hline Some training beyond HS/1 year certificate & 86 & 34.7 & 49 & 37.1 & 37 & 31.9 & & \\
\hline Associate/2-year degree & 21 & 8.5 & 12 & 9.1 & 9 & 7.8 & & \\
\hline 4-year degree or additional training & 44 & 17.7 & 9 & 6.8 & 35 & 30.2 & & \\
\hline Household income $^{\mathrm{d}}$ & & & & & & & $8.40(1)$ & .004 \\
\hline$>150 \%$ FPL and no support & 59 & 23.8 & 18 & 13.6 & 41 & 35.3 & & \\
\hline$<150 \%$ FPL and/or support & 189 & 76.2 & 114 & 86.4 & 75 & 64.7 & & \\
\hline & & & & $\begin{array}{l}\text { oan } \\
=39 \\
0 \%)\end{array}$ & & $\begin{array}{l}\mathrm{ral} \\
=26 \\
0 \%)\end{array}$ & $\begin{array}{l}\text { Urban vs. } \\
\text { comparis }\end{array}$ & $\begin{array}{l}\text { rural } \\
\text { ison }\end{array}$ \\
\hline Preschool teachers & $\mathrm{N}$ & $\%$ & $\mathrm{~N}$ & $\%$ & $\mathrm{~N}$ & $\%$ & $\chi^{2} /$ LRT (df) & $p$ \\
\hline Gender & & & & & & & $0.01(1)$ & .931 \\
\hline Female & 64 & 98.5 & 38 & 97.4 & 26 & 100.0 & & \\
\hline Male & 1 & 1.5 & 1 & 2.6 & 0 & 0.0 & & \\
\hline Race/ethnicity & & & & & & & $1.64(2)$ & .441 \\
\hline Black & 1 & 1.6 & 1 & 2.6 & 0 & 0.0 & & \\
\hline Hispanic or Latino & 3 & 4.7 & 2 & 5.1 & 1 & 4.0 & & \\
\hline Other & 0 & 0.0 & 0 & 0.0 & 0 & 0.0 & & \\
\hline White & 60 & 93.8 & 36 & 92.3 & 24 & 96.0 & & \\
\hline Years of experience & & & & & & & $7.74(2)$ & .021 \\
\hline Fewer than 5 years & 16 & 25.0 & 11 & 28.9 & 5 & 19.2 & & \\
\hline $5-10$ years & 18 & 28.1 & 14 & 36.8 & 4 & 15.4 & & \\
\hline More than 10 years & 30 & 46.9 & 13 & 34.2 & 17 & 65.4 & & \\
\hline Highest level of education & & & & & & & $8.22(2)$ & .016 \\
\hline Associate/2-year degree & 1 & 1.5 & 0 & 0.0 & 1 & 3.8 & & \\
\hline 4-year degree & 38 & 58.5 & 21 & 53.8 & 17 & 65.4 & & \\
\hline Education specialist or master's & 26 & 40 & 18 & 46.2 & 8 & 30.7 & & \\
\hline Teaching certificate & & & & & & & Insufficient ve & variability \\
\hline No & 3 & 4.7 & 0 & 0.0 & 3 & 12.0 & & \\
\hline Yes & 61 & 95.3 & 39 & 100.0 & 22 & 88.0 & & \\
\hline
\end{tabular}


Table 1 (continued) Characteristics of parents and teachers across urban and rural settings

\begin{tabular}{|c|c|c|c|c|c|c|c|c|}
\hline \multirow[b]{2}{*}{ Kindergarten teachers } & \multicolumn{2}{|c|}{$\begin{array}{c}\text { Total } \\
\mathrm{N}=122 \\
(100 \%)\end{array}$} & \multicolumn{2}{|c|}{$\begin{array}{c}\text { Urban } \\
\mathrm{N}=75 \\
(61.5 \%)\end{array}$} & \multicolumn{2}{|c|}{$\begin{array}{c}\text { Rural } \\
\mathrm{N}=47 \\
(38.5 \%)\end{array}$} & \multicolumn{2}{|c|}{$\begin{array}{l}\text { Urban vs. rural } \\
\text { comparison }\end{array}$} \\
\hline & $\mathrm{N}$ & $\%$ & $\mathrm{~N}$ & $\%$ & $\mathrm{~N}$ & $\%$ & $\chi^{2} /$ LRT (df) & $p$ \\
\hline Gender & & & & & & & Insufficient var & ability \\
\hline Female & 118 & 99.2 & 71 & 98.6 & 47 & 100.0 & & \\
\hline Male & 1 & 0.8 & 1 & 1.4 & 0 & 0.0 & & \\
\hline Race/ethnicity & & & & & & & $9.12(3)$ & .028 \\
\hline Black & 1 & 0.9 & 1 & 1.4 & 0 & 0.0 & & \\
\hline Hispanic or Latino & 3 & 2.6 & 2 & 2.8 & 1 & 2.2 & & \\
\hline Other ${ }^{c}$ & 2 & 1.7 & 2 & 2.8 & 0 & 0.0 & & \\
\hline White & 111 & 94.9 & 66 & 93.0 & 45 & 97.8 & & \\
\hline Years of experience & & & & & & & $0.28(2)$ & .869 \\
\hline Fewer than 5 years & 23 & 18.9 & 15 & 20.8 & 8 & 17.0 & & \\
\hline $5-10$ years & 29 & 23.8 & 17 & 23.6 & 12 & 25.5 & & \\
\hline More than 10 years & 67 & 54.9 & 40 & 55.6 & 27 & 57.4 & & \\
\hline Highest level of education & & & & & & & $8.22(2)$ & .016 \\
\hline Associate/2-year degree & 0 & 0.0 & 0 & 0.0 & 0 & 0.0 & & \\
\hline 4-year degree & 63 & 51.6 & 40 & 55.6 & 23 & 48.9 & & \\
\hline Education specialist or master's & 56 & 45.9 & 32 & 44.5 & 24 & 51.1 & & \\
\hline Teaching certificate & & & & & & & Insufficient va & iability \\
\hline No & 0 & 0.0 & 0 & 0.0 & 0 & 0.0 & & \\
\hline Yes & 119 & 100.0 & 72 & 100.0 & 47 & 100.0 & & \\
\hline
\end{tabular}

Geographic comparisons based on multinomial logistic regression analyses with cluster-robust standard errors to account for nesting at the school level

$\chi^{2}$ Chi square difference test (for comparisons based on 1 degree of freedom), LRT likelihood ratio test (for comparisons based on $>1$ degree of freedom), $d f$ degrees of freedom

a. Grandmother, stepmother, great-grandmother

b. Arabic, Chinese, Dinka, French, Karen, Kurdish, Ogoni, Spanish, Vietnamese, multiple languages

c. American Indian/Alaska Native, Asian, Native Hawaiian/Other Pacific Islander, Other, or multiple races

d. Government sources of income/support include welfare, TANF, general assistance, food stamps, WIC, unemployment insurance, SSI or Social Security Retirement, Disability, or Survivor's benefits

school based functions) and home-school conferencing (family- school communication about children's successes and challenges). For the current study, we have reconceptualized the "conferencing" factor as one tapping "structural communication" given its primary focus assessing communication between parents and teachers about school. Items are rated on a 4-point Likert-type scale $(1=$ rarely; $2=$ sometimes; $3=$ often; $4=$ always $) ; t$-scores are generated for each factor $(M=50, S D=10)$. For this study, internal consistency of scores is strong for each time point (i.e., $\alpha=.87-.88$ for home-based involvement, $\alpha=.79-.86$ for schoolbased involvement, $\alpha=.87-.90$ for structural communication). 


\section{Parent-Teacher Relationship Scale-II}

The Parent-Teacher Relationship Scale-II (PTRS-II; Vickers and Minke 1995) contains 24 items that assess two specific relationship constructs: joining (mutual respect, dependability, and shared expectations) and communication-to-other (respondent's view of their communicative contribution to the relationship; Vickers and Minke 1995). The scale assesses the overall quality of the parent-teacher relationship. For purposes of the present study, we reconceptualized the "communication to other" factor as one tapping "relational communication" given its emphasis on parents' communication with the teacher regarding the parentteacher relationship. Each item is scored on a 5-point Likert-type scale and rated as: $1=$ Almost Never; $2=$ Once in a While; $3=$ Sometimes; $4=$ Frequently; $5=$ Almost Always. Given our interest in communication as a tangible action within the parent-teacher relationship, we utilized the parent's report of the communication factor only. Internal consistency estimates for this factor are $\alpha=.84$ (T1), $\alpha=.86$ (T2), and $\alpha=.89$ (T3).

\section{Covariates}

Parent and family covariates were derived from the parent demographic form administered at each time point and included in analyses as follows. Household income status was dichotomized as (a) below 150\% federal poverty level (FPL) and/or received one or more sources of government income/support (e.g., welfare; food stamps; nutrition program support; unemployment insurance) at one or more data collection time points, versus (b) above $150 \%$ FPL and did not receive any support at all data collection time points. Parent race/ethnicity was self-reported and categorized as White, Black, Hispanic, or other race/ethnicity (other race not listed above or multiple races). Parents highest reported education was categorized as (a) less than a high school diploma/GED; (b) high school diploma/GED; (c) some college or a certificate; (d) 2-year college degree; or (e) 4-year college degree or greater. Parent-reported language spoken most often at home with the child was coded as (a) English only at all time points, or (b) another language or multiple languages at one or more time points. 


\section{Analytic Approach}

Cross-classified multilevel modeling was performed to address the study questions while accounting for dependency among observations due to multiple time points nested within children/parents, and children/parents crossed with pre-K and kindergarten classrooms and schools. Analyses were carried out using the MIXED procedure in the SAS/ STAT $®$, Version 9.4 software environment, with restricted maximum likelihood (REML) estimation and Kenward-Rogers denominator degrees of freedom. The MIXED procedure uses all available data such that cases were retained in the analysis if they had outcome data for at least one time point and nonmissing covariates (four cases were dropped resulting in $N=248$ ). Because this study focused on trajectories of parent-report measures over time, a very small number (1\%) of time-level observations were omitted due to the parent respondent changing over time (e.g., if the mother responded at Times 1 and 3 and the father responded at Time 2 , the Time 2 data were omitted). Statistical significance was assessed at the $\alpha=.05$ level. Cohen's $d$ was estimated as a measure of effect size, with the denominator based on the population standard deviation for the FIQ $t$-scores and the pooled sample standard deviation at Time 1 for the PTRS.

\section{Results}

Parameter estimates for the four family engagement models are provided in Table 2 . There were no significant time by geographic context interactions, so time and context associations are discussed separately below.

\section{Does Family Engagement (Home- and School-Based Involvement; Structural and Relational Communication) Change from Entry into Pre-K Through the Kindergarten Year?}

Figure 1 illustrates the model-predicted family engagement scores and 95\% confidence intervals across each of the three study time points. There was a significant positive linear association between time and parents' report of their homebased involvement $(b=1.24, \mathrm{SE}=$ 
Table 2 Cross-classified multilevel model parameter estimates

\begin{tabular}{|c|c|c|c|c|c|c|c|c|c|c|c|c|}
\hline \multirow[t]{2}{*}{ Fixed effects } & \multicolumn{3}{|c|}{ Home-based involvement } & \multicolumn{3}{|c|}{ School-based involvement } & \multicolumn{3}{|c|}{ Structural communication } & \multicolumn{3}{|c|}{ Relational communication } \\
\hline & $\mathrm{b}$ & SE & $p$ & $\mathrm{~b}$ & SE & $p$ & $\mathrm{~b}$ & SE & $p$ & $\mathrm{~b}$ & $\mathrm{SE}$ & $p$ \\
\hline Intercept & 51.11 & 2.22 & $<.001$ & 45.54 & 1.79 & $<.001$ & 54.33 & 2.14 & $<.001$ & 4.32 & 0.20 & $<.001$ \\
\hline Time & 1.24 & 0.55 & .027 & 5.81 & 1.71 & $<.001$ & 2.81 & 2.11 & .184 & 0.39 & 0.23 & .093 \\
\hline Time $\times$ Time & - & - & - & -5.33 & 1.46 & $<.001$ & -3.59 & 1.79 & .045 & -0.45 & 0.20 & .023 \\
\hline Geographic context & $\mathrm{t}-4.90$ & 1.46 & $<.001$ & -0.98 & 1.26 & .438 & -6.41 & 1.46 & $<.001$ & -0.29 & 0.14 & .039 \\
\hline Income & 0.06 & 1.62 & .969 & 0.64 & 1.28 & .620 & -1.65 & 1.56 & .290 & -0.14 & 0.14 & .332 \\
\hline Race/ethnicity & $\begin{array}{c}\mathrm{F}(3,237)=3.29, \\
p=.021^{\mathrm{a}}\end{array}$ & & & $\begin{array}{c}\mathrm{F}(3,240)=2.28 \\
p=.080\end{array}$ & & & $\begin{array}{c}\mathrm{F}(3,229)=2.86 \\
p=.038^{\mathrm{b}}\end{array}$ & & & $\begin{array}{c}(3,225)=0 . \\
p=.806\end{array}$ & & \\
\hline Black & 2.42 & 1.93 & .211 & 3.72 & 1.57 & .019 & 3.85 & 1.88 & .042 & 0.14 & 0.17 & .421 \\
\hline Hispanic & 4.01 & 2.04 & .050 & 1.12 & 1.62 & .491 & 2.65 & 1.96 & .178 & 0.02 & 0.18 & .905 \\
\hline Other & -3.57 & 2.57 & .166 & -0.65 & 2.05 & .750 & -2.37 & 2.47 & .340 & -0.07 & 0.22 & .742 \\
\hline Education & $\begin{array}{c}(4,235)=1.08 \\
p=.367\end{array}$ & & & $\begin{array}{c}\mathrm{F}(4,229)=1.41 \\
p=.232\end{array}$ & & & $\begin{array}{c}\mathrm{F}(4,235)=1.95 \\
p=.103\end{array}$ & & & $\begin{array}{c}(4,233)=1 . \\
p=.288\end{array}$ & & \\
\hline$<$ HS diploma & -2.23 & 2.55 & .383 & -3.23 & 2.02 & .111 & -3.93 & 2.45 & .111 & -0.28 & 0.22 & .208 \\
\hline HS diploma & 1.26 & 1.99 & .526 & -1.61 & 1.57 & .307 & 0.02 & 1.91 & .992 & 0.09 & 0.17 & .614 \\
\hline Some college & -0.94 & 1.89 & .619 & -3.21 & 1.49 & .033 & -3.00 & 1.82 & .100 & 0.11 & 0.16 & .514 \\
\hline 2-year degree & -2.07 & 2.57 & .422 & -1.76 & 2.04 & .390 & -3.26 & 2.48 & .190 & 0.02 & 0.22 & .942 \\
\hline Home language & -4.16 & 2.04 & .043 & -2.52 & 1.63 & .123 & -2.79 & 1.97 & .157 & -0.30 & 0.18 & .090 \\
\hline Variance terms & & & Est. & & & Est. & & & Est. & & & Est. \\
\hline Pre-K school-level & & & - & & & 3.54 & & & 1.55 & & & 0.01 \\
\hline K school-level & & & - & & & 1.78 & & & - & & & 0.07 \\
\hline Pre-K teacher-level & & & 3.99 & & & 1.60 & & & 0.65 & & & 0.04 \\
\hline K teacher-level & & & 1.38 & & & 12.60 & & & 35.85 & & & 0.21 \\
\hline Child-level & & & 65.74 & & & 39.43 & & & 58.93 & & & 0.41 \\
\hline Residual & & & 37.95 & & & 22.69 & & & 34.91 & & & 0.43 \\
\hline
\end{tabular}

Time in months from the beginning of the school year was centered at the average fall pre-K parent assessment time point. Reference groups were urban, low income, White, 4-year degree or higher, and English-only home language. Dashes indicate effect was not included in model a. Parents who identified as Black reported significantly greater home-based involvement than parents who were classified as "other" race/ethnicity ( $\mathrm{b}=5.99, \mathrm{SE}=2.78, p=.032$ ) and parents who identified as Hispanic reported significantly greater home-based involvement than parents who were classified as "other" $(\mathrm{b}=7.58, \mathrm{SE}=2.80, p=.007)$

b. Parents who identified as Black reported significantly greater structural communication than parents who were classified as "other" (b=6.22, $\mathrm{SE}=2.68, p=.021)$ and parents who identified as White $(\mathrm{b}=3.85, \mathrm{SE}=1.88, p=.042)$

$0.55, p=.027$ ), with scores increasing on average by .04 SD units from fall of pre-K to spring of pre-K and .10 SD units from spring of pre-K to spring of kindergarten. Significant quadratic associations of time were observed for parents' report of their school-based involvement $(\mathrm{b}=-$ $5.33, \mathrm{SE}=1.46, p<.001)$, structural communication $(\mathrm{b}=-3.59, \mathrm{SE}=$ 

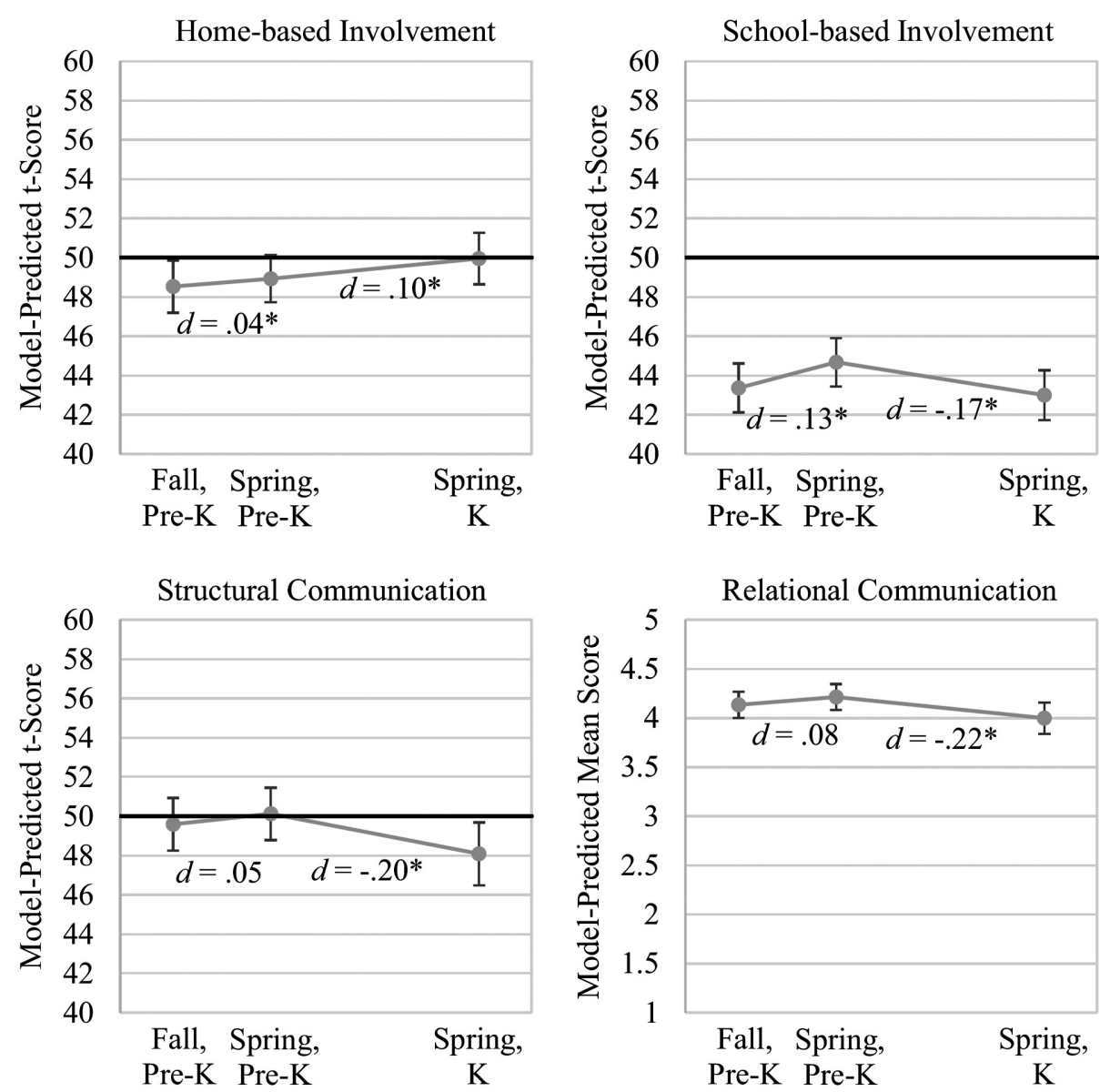

Fig. 1 Model-predicted family engagement scores and 95\% confidence intervals by study time point. Covariates held constant at the sample mean. Solid horizontal line indicates population mean of FIQ $\mathrm{t}$-scores. $d=$ Cohen's $\mathrm{d}$ for time main effect (fall pre-K vs. spring pre-K; spring pre-K vs. spring kindergarten). ${ }^{*} p<.05$ for time main effect

$1.79, p=.045)$, and relational communication $(\mathrm{b}=-0.45, \mathrm{SE}=0.20, p$ $=.023$ ). School-based involvement scores increased on average by .13 SD units from fall of pre- $\mathrm{K}$ to spring of pre- $\mathrm{K}$, but decreased by an average of .17 SD units from spring of pre-K to spring of kindergarten. Structural and relational communication scores did not change on average across pre-K but significantly decreased by an average of .20 SD units (structural) and .22 units (relational) from spring of pre-K to spring of kindergarten. 

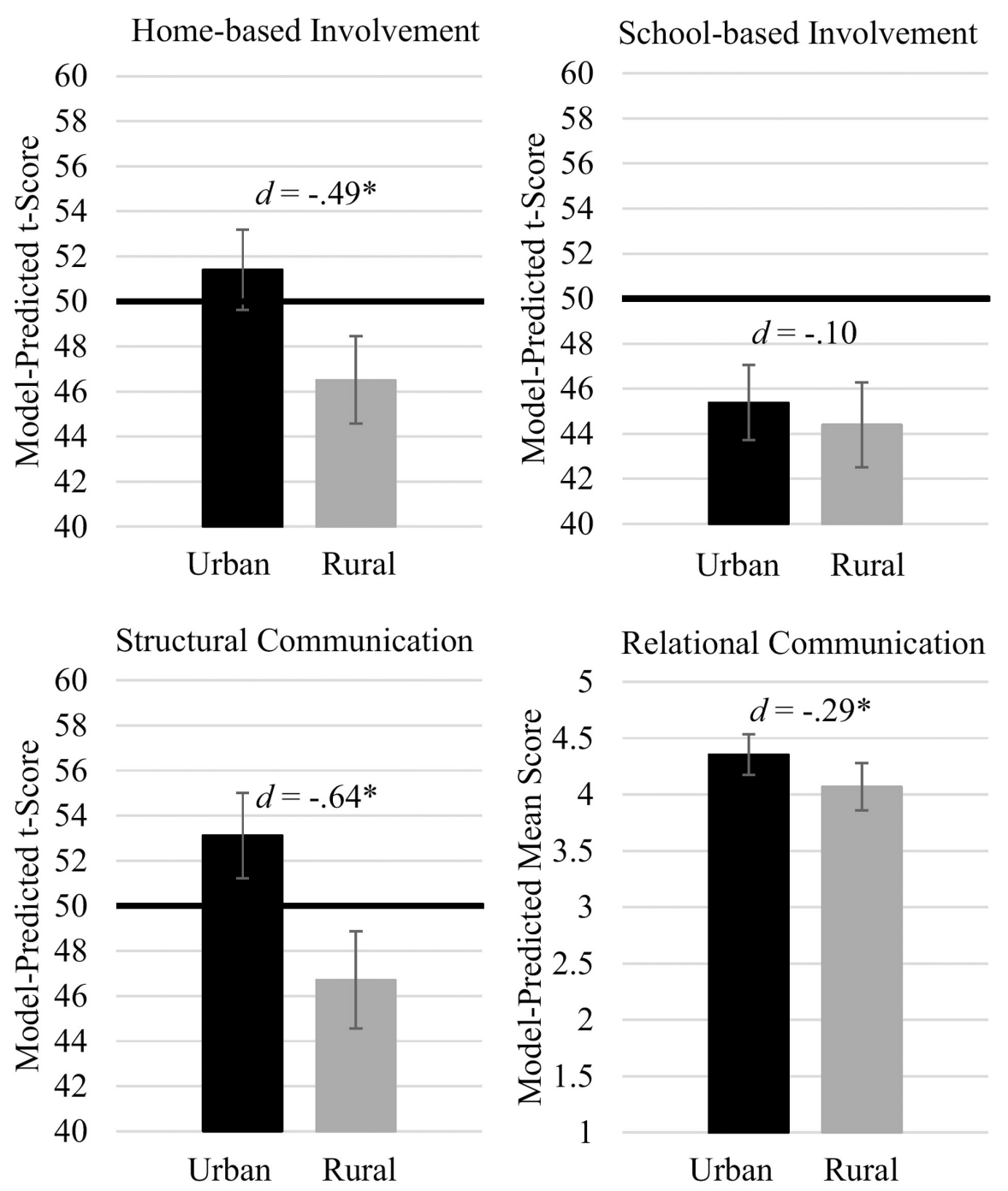

Fig. 2 Model-predicted family engagement scores and 95\% confidence intervals by geographic context. Covariates held constant at the sample mean. Solid horizontal line indicates population mean of FIQ $\mathrm{t}$-scores. $d=$ Cohen's $\mathrm{d}$ for geographic context main effect. ${ }^{*} p<.05$ for geographic context main effect

\section{Involvement; Structural and Relational Communication) Differ for Children in Rural Versus Urban Schools?}

Figure 2 illustrates the model-predicted family engagement scores and $95 \%$ confidence intervals by geographic context. On average, parents of children who attended school in an urban community setting reported greater home-based involvement $(\mathrm{b}=-4.90, \mathrm{SE}=1.46, p<.001$, 
$d=-0.49)$, structural communication $(\mathrm{b}=-6.41, \mathrm{SE}=1.46, p<.001$, $d=-0.64)$, and relational communication ( $\mathrm{b}=-0.29, \mathrm{SE}=0.14, p=.039$, $d=-0.29$ ) than parents of children who attended school in a rural setting. There were no significant differences in school-based involvement by geographic context.

\section{Discussion}

This study explored the nature of parent engagement from an ecological lens. We investigated practices at the level of the microsystem (i.e., home-based and school-based involvement) and mesosystem (i.e., parent-teacher connection), as well as exosystem (i.e., rural/urban locale) and chronosystem (i.e., pre-K to kindergarten transition). The results of this study reveal important patterns of parent engagement in children's learning within and across children's earliest formal learning experiences over time, and differences between geographic contexts.

\section{Patterns of Family Engagement}

Meta-analyses show consistently the benefits of parenting practices and home-based learning approaches (such as family literacy activities, talking to children about school) on academic (Kim and Quinn 2013; van Steensel et al. 2011) and social-emotional (Sheridan et al. 2019) competencies for children across pre-K, elementary, and secondary grades. Our findings suggest the manner in which parents support their child's early learning as they transition to kindergarten in one Midwestern state changes over time. Significant increases in home-based involvement is evident from pre-K through kindergarten. Given the time and opportunities parents provide their children, activities in the home environment represent a malleable factor that can augment learning. Even when children receive high quality experiences in multiple settings (e.g., pre-K, elementary school classrooms), optimal learning outcomes require additional positive stimulation in the home (Crosnoe et al. 2010). Thus, although the change over time is considered small, the consistent increase in home-based involvement from the beginning of pre-K through the end of kindergarten is an important and encouraging pattern.

Consistent with some previous research (e.g., Daniel 2015; Murray et al. 2015), our data indicate that parental school-based engagement and 
communication with teachers decline over time. These forms of engagement that tangibly link home and school yield unique opportunities that may benefit children's learning (Waanders et al. 2007), so the small but significant decelerating patterns in both structural and relational communication from pre-K to kindergarten may raise concern. Unpacking the trajectories a bit more, it is evident for the current sample that patterns of self-reported involvement in school-based activities (e.g., events occurring at school) and communication changed from the start to the end of pre-K to the end of kindergarten. Whereas early childhood programs may offer consistent opportunities for parents to engage over the course of the pre-K year, kindergarten classrooms are often more structured and routinized in academic content than most pre-K classrooms. Relative to pre-K settings, parents of kindergarten students may experience less opportunities for face-to-face contact and communication, fewer welcoming messages and practices, and fewer policy guidelines related to parent engagement. These contextual differences may attenuate kindergarten parents' engagement in the school setting, and in communication efforts with their child's kindergarten teacher. Future research would benefit from discerning the specific activities or communication practices adopted by parents early on, how these may transfer to kindergarten and beyond, and how they relate to child outcomes over time.

\section{Influence of Geographic Context}

This study reinforces other studies that have reported the importance of community and geographic context vis-à-vis family engagement. Indeed, the consistent differences in the nature and amount of family engagement in our urban versus rural samples are noteworthy. Generally speaking, for families in the current study, engagement in children's learning in rural communities is lower than in urban settings. Geographic location may be expected to affect only some forms of engagement (e.g., school-based involvement), yet our data suggest that is not the case. Rural parents reported significantly less engagement than urban parents in homebased involvement with a moderate effect size indicating the importance of geographical context in parenting practices in the home. Likewise, geographic context had a medium to large impact on the structural communications parents reported with teachers, with rural parents reporting significantly less than urban parents. These forms of engagement (i.e., home-based involvement, structural 
communication) do not appear to be contingent on proximity to schools, yet rural parents reported significantly less involvement with these types of practices than did urban parents. Certain structural communications between schools and homes rely increasingly on internet-based methods, however reliable and efficient broadband is significantly more limited in rural compared to other geographic areas nationally (Microsoft 2017). Diminishing communications may also limit rural families' perceptions of their roles in their children's early education, including those practiced at home. Greater research attention to rural parents' expectations and motivations for engagement, and how their community context may influence these role constructs, is needed.

Small but significant differences between rural and urban parents' reports of relational communication were also revealed, with urban parents reporting greater frequency of this form of engagement. It is possible that the difference in relational communication is due to limited access to and opportunities for parent-teacher partnership-building and support in rural versus urban communities. For example, in some rural communities, the geographic distance between school buildings and families' homes may limit parent and teacher time for collaborative, relationship-building meetings (Kushman and Barnhardt 2001). If parents and teachers face long commutes to and from the school, time for faceto-face meetings is reduced and communication may be limited to brief notes or phone calls home (McBride et al. 2002). This interpretation is tempered to some degree by our finding of no difference between rural and urban parents' reports of school-based involvement, however this form of engagement was low across settings.

Our findings add to the literature creating a better picture of early parenting practices in rural communities over time. Despite the many strengths associated with rural communities, our study corroborates previous research reporting significant differences in parent engagement practices in rural versus urban communities (Keys 2015). A large metaanalysis found that the effects of family-school interventions on children's social-behavioral competency and mental health were greatest for rural children, possibly due to the increased social capital gained when families and schools work together in under-resourced settings (Sheridan et al. 2019). Our current findings revealing significantly less engagement for rural families represents a missed opportunity to support children in rural schools, and identifies a dire need to establish relevant and meaningful roles for rural families. 


\section{Study Limitations}

The current study provides deeper understanding about multidimensional aspects of family engagement (i.e., home- and school-based involvement, and structural and relational communication) across urban and rural settings and during the pre-K to kindergarten transition than what has been available heretofore. However, it is not without its limitations. This study is based on one state in the Midwest, so the sample is not representative of all parts of the country, and all urban and rural communities. Given the significant variability across rural and urban settings, the study requires replication in order to draw generalizable conclusions. A second concern aligns with the source of information in the current study. Specifically, family engagement in this study was reported by parents only. Teachers' perceptions of parents' involvement at school, or communication between parents and teachers, were not included in this study. The method used to collect data was self-report only, with no corroborating observational or direct measures of engagement collected. These source and method biases require attention prior to concluding with confidence the reliability of the present data. Third, assessments were conducted twice in pre- $K$, but only once in kindergarten.

A final limitation of this study is the measure used to assess homebased family engagement. The FIQ was originally developed for use with a sample of urban families, primarily English-speaking. Thus, the items might be more reflective of practices and activities appropriate for families in urban and not rural settings, and for English-speaking families. Further exploration of the relevance of this measure for culturally and linguistically diverse and rural samples is a direction for future research.

\section{Future Directions}

Family engagement has been posited as one strategy to support children's cognitive, behavioral, socioemotional development, and school readiness. Whereas there is reason to be optimistic given the increase in home-based involvement from pre-K to kindergarten, trends in other family engagement areas (e.g., school-based involvement, structural communication) are concerning. Decreases in the amount and quality of communication during the kindergarten year may illuminate a concerning trend in need of further investigation. There is a need for future studies to examine whether qualitative differences exist in how parents and 
schools view family engagement across different geographic contexts. Studies are needed examining the links between family engagement and children's development and learning across the pre-K to kindergarten years, and whether they vary across community contexts. Family engagement has the child at the center; thus understanding variations in children's needs as they relate to engagement is important. This will illuminate potential similarities and differences in how family engagement may be related to children's development and learning, and variations due to contexts, which has implications for interventions.

Acknowledgments - The research reported here was supported by the Institute of Education Sciences, U.S. Department of Education, through Grant \#R305N160016 to the University of Nebraska-Lincoln. The opinions expressed are those of the authors and do not represent views of the Institute or the U.S. Department of Education.

\section{References}

Arnold, D. H., Zeljo, A., Doctoroff, G. L., \& Ortiz, C. (2008). Parent involvement in preschool: Predictors and the relation of involvement to preliteracy development. School Psychology Review, 37, 74-90.

Bronfenbrenner, U. (1977). Toward an experimental ecology of human development. American Psychologist, 32, 513-531. https://doi. org/10.1037/0003-066X.32.7.513

Microsoft Corporation. (2017). A rural broadband strategy: Connecting rural America to new opportunities. Redmond, WA: Microsoft Corporation.

Crosnoe, R., Morrison, F., Burchinal, M., Pianta, R., Keating, D., Friedman, S. L., et al. (2010). Instruction, teacher-student relations, and math achievement trajectories in elementary school. Journal of Educational Psychology, 102, 407-417. https:// doi.org/10.1037/a0017762

Daniel, G. (2015). Patterns of parent involvement: A longitudinal analysis of familyschool partnerships in the early years of school in Australia. Australasian Journal of Early Childhood, 40, 119-128.

Denham, S. A., Bassett, H. H., \& Wyatt, T. (2007). The socialization of emotional competence. In J. E. Grusec \& P. D. Hastings (Eds.), Handbook of socialization: Theory and research (pp. 614-637). New York, NY: Guilford.

Fantuzzo, J., Tighe, E., \& Childs, S. (2000). Family involvement questionnaire: A multivariate assessment of family participation in early childhood education. Journal of Educational Psychology, 92, 367-376. https://doi. org/10.1037/0022-0663.92.2.367 
Forget-Dubois, N., Dionne, G., Lemelin, J. P., Pérusse, D., Tremblay, R. E., \& Boivin, M. (2009). Early child language mediates the relation between home environment and school readiness. Child Development, 80, 736-749. https://doi. org/10.1111/j.1467-8624.2009.01294.X

Hart, B., \& Risley, T. R. (1995). Meaningful differences in the everyday experience of young American children. Baltimore, MD: Brookes.

Hindman, A. H., \& Morrison, F. J. (2012). Differential contributions of three parenting dimensions to preschool literacy and social skills in a middle-income sample. Merrill-Palmer Quarterly, 58, 191-223.

Keys, A. (2015). Family engagement in rural and urban head start families: An exploratory study. Early Childhood Education Journal, 43, 69-76. https://doi. org/10.1007/s1064 3-014-0643-8

Kim, J. S., \& Quinn, D. M. (2013). The effects of summer reading on low-income children's literacy achievement from kindergarten to grade 8: A meta-analysis of classroom and home interventions. Review of Educational Research, 83, 386-431. https://doi.org/10.3102/00346543131483906

Kohl, G. O., Lengua, L. J., \& McMahon, R. J. (2000). Parent involvement in school conceptualizing multiple dimensions and their relations with family and demographic risk factors. Journal of School Psychology, 38, 501-523.

Kushman, J. W., \& Barnhardt, R. (2001). Reforming education from the inside-out: A study of community engagement and educational reform in rural Alaska. Journal of Research in Rural Education, 17, 12-26.

Lang, S. N., Tolbert, A. R., Schoppe-Sullivan, S. J., \& Bonomi, A. E. (2016). A cocaring framework for infants and toddlers: Applying a model of coparenting to parentteacher relationships. Early Childhood Research Quarterly, 34, 40-52. https://doi. org/10.1016/j.ecres q.2015.08.004

Lavalley, M. (2018). Out of the loop: Rural schools are largely left out of research and policy discussions, exacerbating poverty, inequity, and isolation. Alexandria: Center for Public Education.

Lee, J., \& Bowen, N. K. (2006). Parent involvement, cultural capital, and the achievement gap among elementary school children. American Educational Research Journal, 43, 193-218.

Malsch, A. M., Green, B. L., \& Kothari, B. H. (2011). Understanding parents' perspectives on the transition to kindergarten. Best Practices in Mental Health, 7, 47-66.

Margetts, K. (2009). Early transition and adjustment and children's adjustment after six years of schooling. European Early Childhood Education Research Journal, 17, 309-324. https://doi.org/10.1080/13502930903101511

McBride, B. A., Bae, J.-H., \& Wright, M. S. (2002). An examination of family-school partnership initiatives in rural prekindergarten programs. Early Education and Development, 13, 107-127. https://doi.org/10.1207/s15566935eed1301 6

McClelland, M. M., Acock, A. C., \& Morrison, F. J. (2006). The impact of kindergarten learning-related skills on academic trajectories at the end of elementary school. Early Childhood Research Quarterly, 21, 471-490. https://doi.org/10.1016/j. ecresq.2006.09.003 
Miller, P., \& Votruba-Drzal, E. (2013). Early academic skills and childhood experiences across the urban-rural continuum. Early Childhood Research Quarterly, 28, 234-248. https://doi.org/10.1016/j.ecresq.2012.12.005

Murray, E., McFarland-Piazza, L., \& Harrison, L. J. (2015). Changing patterns of parent-teacher communication and parent involvement from preschool to school. Early Child Development and Care, 185, 1031-1052. https://doi. org/10.1080/03004 430.2014.975223

Napoli, A. R., \& Purpura, D. J. (2018). The home literacy and numeracy environment in preschool: Cross-domain relations of parent- child practices and child outcomes. Journal of Experimental Child Psychology, 166, 581-603. https://doi. org/10.1016/i.jecp.2017.10.002

National Academies of Science, Engineering and Medicine. (2016). Parenting matters: Supporting parents of children ages $0-8$. Washington, DC: The National Academies Press.

Office of Management and Budget. (2000). Standards for Defining Metropolitan and Micropolitan Statistical Areas; Notice. Federal Register (65) No. 249.

Player, D. (2016). The supply and demand for rural teachers. Boise, ID: Rural Opportunities Consortium of Idaho.

Prater, D. L., Bermudez, A. B., \& Owens, E. (1997). Examining parental involvement in rural, urban, and suburban schools. Journal of Research in Rural Education, 13, 72-75.

Schulting, A. B., Malone, P. S., \& Dodge, K. A. (2005). The effect of schoolbased kindergarten transition policies and practices on child academic outcomes. Developmental Psychology, 41, 860- 871. https://doi. org/10.1037/0012-1649.41.6.860

Semke, C. A., \& Sheridan, S. M. (2012). Family-school connections in rural educational settings: A systematic review of the empirical literature. School Community Journal, 22(1), 21-48.

Sénéchal, M. (2006). The effect of family literacy interventions on children's acquisition of reading: From kindergarten to grade 3 (meta-analytic review). Portsmouth, NH: RMC Research Corporation.

Sheridan, S. M., Bovaird, J. A., Glover, T. A., Garbacz, S. A., Witte, A., \& Kwon, K. (2012). A randomized trial examining the effects of conjoint behavioral consultation and the mediating role of the parent- teacher relationship. School Psychology Review, 41, 23-46.

Sheridan, S. M., Knoche, L. L., Edwards, C. P., Bovaird, J. A., \& Kupzyk, K. A. (2010). Parent engagement and school readiness: Effects of the Getting Ready intervention on preschool children's social-emotional competencies. Early Education and Development, 21, 125-156.

Sheridan, S. M., Knoche, L. L., Kupzyk, K. A., Edwards, C. P., \& Marvin, C. A. (2011). A randomized trial examining the effects of parent engagement on early language and literacy: The Getting Ready intervention. Journal of School Psychology, 49, 361-383. https://doi.org/10.1016/j.jsp./2011.03.001 
Sheridan, S. M., Smith, T. E., Kim, E. M., Beretvas, S. N., \& Park, S. (2019). A meta-analysis of family-school interventions and children's socialemotional functioning: Child and community influences and components of efficacy. Review of Educational Research., 89, 296-332. https://doi. org/10.3102/0034654318825437

Sheridan, S. M., Witte, A. L., Holmes, S. R., Coutts, M. J., Dent, A. L., Kunz, G. M., et al. (2017a). A randomized trial examining the effects of conjoint behavioral consultation in rural schools: Student outcomes and the mediating role of the teacher-parent relationship. Journal of School Psychology, 61, 33-53. https://doi. org/10.1016/i.jsp.2016.12.002

Sheridan, S. M., Witte, A. L., Holmes, S. R., Wu, C., Bhatia, S. A., \& Angell, S. R. (2017b). The efficacy of conjoint behavioral consultation in the home setting: Outcomes and mechanisms in rural communities. Journal of School Psychology, 62, 81-101. https://doi.org/10.1016/j.jsp.2017.03.005

Sheridan, S. M., Witte, A. L., Kunz, G. M., Wheeler, L. A., Angell, S. R., \& Lester, H. (2018). Rural teacher practices and partnerships to address behavioral challenges: The efficacy and mechanisms of conjoint behavioral consultation. The Elementary School Journal, 119, 99-121. https://doi.org/10.1086/698694

Showalter, D., Klein, R., Johnson, J., \& Hartman, S. L. (2017). Why rural matters 20152016: Understanding the changing landscape. Washington, DC: Rural School and Community Trust.

Van Steensel, R., McElvany, N., Kurvers, J., \& Herppich, S. (2011). How effective are family literacy programs?: Results of a metaanalysis. Review of Educational Research, 81, 69-96.

Vickers, H. S., \& Minke, K. M. (1995). Exploring parent-teacher relationships: Joining and communication to others. School Psychology Quarterly, 10, 133-150. https:// doi.org/10.1037/h0088300

Waanders, C., Mendez, J. L., \& Downer, J. T. (2007). Parent characteristics, economic stress and neighborhood context as predictors of parent involvement in preschool children's education. Journal of School Psychology, 45, 619-636.

Weigel, D. J., Martin, S. S., \& Bennett, K. K. (2006). Mothers' literacy beliefs: Connections with the home literacy environment and pre-school children's literacy development. Journal of Early Childhood Literacy, 6, 191-211. https://doi. org/10.1177/1468798406066444 